\title{
"Serei pai, e agora?" Perspectivas de adolescentes masculinos na vivência da paternidade
}

\author{
"I'm going to be a father, and now?" \\ Prospects of male teenagers in the experience of parenthood
}

\section{Gabriella LACERDA \\ MAgALHÃES ${ }^{1}$ \\ Lívia Alencar Gomes ${ }^{\text {II }}$ \\ Rosana Franciele Botelho RUAS ${ }^{\text {III }}$ \\ Antônia Gonçalves de Souza ${ }^{\mathrm{IV}}$ \\ Luís Paulo Souza e Souza \\ Carla Silvana de Oliveira e SILVA $^{\text {VI }}$}

NÁdia Aléssio Velloso

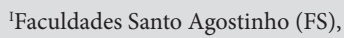
Montes Claros/MG - Brasil.

"Faculdades Santo Agostinho (FS), Montes Claros/MG - Brasil.

IIIInstituto Superior de Educação Ibituruna (ISEIB), Montes Claros/ MG - Brasil.

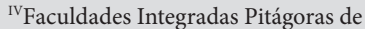
Montes Claros (FIP-MOC), Montes Claros/MG - Brasil.

vUniversidade Federal de São João del-Rei (UFSJ), São João del-Rei/ MG - Brasil.

VIUniversidade Estadual de Montes Claros (UNIMONTES), Montes Claros/MG - Brasil.

VIIUniversidade Federal do Mato Grosso (UFMT), Cuiabá/MT Brasil.
Resumo Introdução: A gravidez precoce e não planejada na adolescência tornou-se um problema de saúde pública no Brasil e no mundo, e apresenta como consequências comprometimentos biológicos, psicológicos e sociais. Nesse contexto, identifica-se uma ênfase nos estudos relacionados à maternidade na adolescência e um distanciamento e silêncio no que se refere ao universo masculino, o que confere certa invisibilidade ao pai adolescente.

Objetivo: Compreender a experiência da paternidade para adolescentes masculinos atendidos por uma Estratégia Saúde da Família.

Métodos: Pesquisa qualitativa, realizada em 2013, com oito pais adolescentes no município de Montes Claros, Minas Gerais - Brasil. Os dados foram coletados por meio de entrevistas abertas e analisados pela técnica de análise de conteúdo.

Resultados: As categorias emergidas foram: "Vivendo a descoberta da gestação: mudanças no estilo de vida, preocupações e expectativas"; "Avaliação da assistência prestada pelo serviço de saúde e participação do pai no pré-natal: entre anseios e exclusão". As principais dificuldades encontradas pelos pais adolescentes foram de natureza psicológica, financeira e, principalmente, no que diz respeito à falta de uma rede social efetiva de apoio.

Conclusão: Os discursos evidenciaram a necessidade de uma nova organização dos serviços de saúde de maneira a introduzir o pai adolescente nesse contexto, para que ele possa contribuir no cuidado à mãe e ao filho, com suas subjetividades e especificidades.

Palavras-chave: Paternidade. Adolescência. Gravidez. RelaÇões Familiares.

Abstract Introduction: Early pregnancy and unplanned teenager has become a public health problem in Brazil and in the world, and presents as a result biological, psychological and social compromises. In this context, identifies an emphasis on studies related to motherhood in adolescence and a coldness and silence with regard to the male universe, which gives certain invisibility to baby daddy.

Objective: To understand the experience of Parenthood for male teenagers met by a Family Health Strategy.

Methods: Qualitative research, held in 2013, with eight teenage parents in the city of Montes Claros, Minas Gerais - Brazil. The data were col- 
lected through interviews and analyzed by content analysis technique. Results: the categories emerged: "Living the discovery of pregnancy: changes in lifestyle, concerns and expectations"; "Evaluation of the assistance provided by the health service and parent participation in prenatal care: between desires and exclusion". The main difficulties encountered by teenage parents were psychological, financial and, above all, as regards the lack of a social network of support.

Conclusion: The speeches came the need for a new organization of health services in order to introduce the baby daddy in this context, so that it can contribute in the mother and son, with its specificities and subjectivities.

Key-words: Fatherhood. Adolescence. Pregnancy. Family Relations.

\section{INTRODUÇÃO}

O último censo realizado pelo Instituto Brasileiro de Geografia e Estatística, em 2010, mostrou que a população brasileira ultrapassou 190 milhões de pessoas. Em relação às faixas etárias, os adolescentes representaram mais de $17 \%$ da população brasileira. ${ }^{1}$ É importante destacar que são considerados adolescentes indivíduos entre 10 anos e 19 anos de idade. ${ }^{2}$

Em 2013, o número de nascidos vivos de mães entre 10 anos e 19 anos de idade foi de 559.484, o que representou $19 \%$ dos nascidos vivos na população. A relevância demográfica chama atenção para as demandas, necessidades e condições de vida dessa parcela da população, destacando-se a importância da gravidez na adolescência, mais especificamente aquela não planejada. ${ }^{3}$

A gravidez precoce e não planejada na adolescência é um problema de saúde pública no Brasil e no mundo, trazendo comprometimentos biológicos, psicológicos e sociais. A ocorrência da gravidez nessa faixa etária revela, ainda, uma sexualidade insegura, com exposição ao vírus da Imunodeficiência Humana (HIV) e outras doenças sexualmente transmissíveis. Além disso, traz impacto na vida familiar e na situação econômica, uma vez que, frequentemente, é motivo para os pais adolescentes se afastarem da escola e amigos, comprometendo sua qualificação, inserção no mercado de trabalho e convivência social. Entende-se que a instabilidade dos vínculos conjugais impacte negativamente e, em muitos casos, acirra a situação de pobreza. ${ }^{4}$ Assim, analisar o contexto e condições de vida desses jovens, em sua grande maioria vulneráveis, torna-se importante. ${ }^{5}$

Observa-se, no entanto, uma ênfase nos estudos relacionados à maternidade na adolescência, e um distanciamento e silêncio no que se refere ao universo masculino, o que confere certa invisibilidade ao pai adolescente. ${ }^{6,7,8}$ Tal desconhecimento pode levar a uma postura social negligente pela família e serviços de saúde e sociedade, gerando nos pais adolescentes maiores dificuldades no desenvolvimento humano e social no processo de paternidade. ${ }^{9}$

Diante disso, objetivou-se analisar a experiência da paternidade para adolescentes masculinos atendidos por uma Estratégia Saúde da Família ao norte do Estado de Minas Gerais, Brasil.

\section{MÉTODo}

Pesquisa qualitativa, realizada com adolescentes masculinos, atendidos por uma Estratégia Saúde da Família (ESF) do município de Montes Claros, norte do Estado de Minas Gerais - Brasil. A seleção dos pais, por meio da Ficha A, foi mediada pelos enfermeiros e agentes comunitários de saúde. 
A coleta dos dados foi realizada no primeiro semestre de 2013 e só concretizada após autorização dos adolescentes e seus pais ou responsáveis. As entrevistas foram conduzidas nos domicílios dos pais adolescentes, tendo como questão norteadora a seguinte: "Conte pra mim como foi sua experiência de ser pai ainda adolescente?". Perguntas de relance foram utilizadas para aprofundar as temáticas surgidas. $\mathrm{O}$ número final de entrevistados foi definido pelo critério de saturação, finalizando em oito pais entrevistados.

As entrevistas foram gravadas e transcritas na íntegra. Para a análise de dados, utilizou-se a técnica de análise de conteúdo de Bardin, ${ }^{10}$ realizada nas seguintes etapas: pré-análise; leitura flutuante; leitura exaustiva; codificação; reorganização dos elementos do texto em unidades de análise; elaboração das categorias.

Este trabalho foi aprovado pelo Comitê de Ética em Pesquisa das Faculdades Unidas do Norte de Minas, protocolo nº 264.485. Todos os participantes, assim como os pais ou responsáveis por eles, assinaram o Termo de Consentimento Livre e Esclarecido.

\section{RESULTADOS E DISCUSSÃO}

Todos os participantes abordados aceitaram participar do estudo, sendo assim, levando em consideração a saturação dos dados, como já descrita na seção Método, oito adolescentes masculinos que vivenciaram a paternidade responderam às entrevistas. Os entrevistados tinham idade entre 15 anos e 18 anos e, seguindo os princípios éticos, foram identificados por pseudonomes (A1 a A8).
A partir das análises das entrevistas, foi possível constatar as seguintes categorias: "Vivendo a descoberta da gestação: mudanças no estilo de vida, preocupações e expectativas"; "Avaliação da assistência prestada pelo serviço de saúde e participação do pai no pré-natal: entre anseios e exclusão"; as quais serão discutas a seguir.

Vivendo a descoberta da gestação: mudanças no estilo de vida, preocupações e expectativas

Identificaram-se nas falas dos pais um misto de sentimentos nas fases de assimilação das realidades que permeiam a paternidade. Inicialmente, com a descoberta da gestação, identificaram-se sentimentos de desespero, tristeza, medo e choque. Porém, com o passar do tempo, sentimentos de resignação e até alegria foram vividos.

Nossa, pra falar a verdade, de início me desesperei, fiquei triste pra caramba. Hoje já estou me acostumando e até gosto da ideia de ser pai, hoje estou feliz (A2).

É dificil falar assim, é uma mistura de alegria, medo, tristeza É tudo junto sabe, só vivendo pra saber (A6).

Quando descobri foi um choque né, não sabia o que fazer. Depois foi normal, foi se ajeitando tudo (A7).

Achei bom demais! Bom demais! Primeiro eu preocupei, depois deixei rolar. Fazer o que, né? O menino já tava vindo. Não tinha mais jeito, era deixar rolar (A3).

Interpreta-se que os padrões sociais requerem dos pais adolescentes papéis e funções que exigem novos comportamentos e maiores responsabilidades. As normas 
sociais imprimem nos sujeitos condutas e responsabilidades que acabam forçosamente anulando os sentimentos da própria pessoa. Nesse sentido, os adolescentes, afetados por uma mudança drástica de papel social, veem-se obrigados a assumir novos modos de vida e obrigações na paternidade, de modo que não é prioritário, nesse momento, sentir e viver plenamente a experiência. ${ }^{11}$

Além das mudanças intrínsecas ao ser adolescente, inúmeras foram as preocupações em relação à paternidade nesse momento. Os relatos, a seguir, dão destaque para a saúde da companheira e do filho; situação financeira; e educação do filho.

É tudo complicado, eu não esperava isso. Preocupava com as "doraiada" que ela sentia, tinha que tá correndo pro hospital mais ela, e os dois novo demais, eu não esperava nada disso não (A5).

Preocupo muito porque não tenho um trabalho fixo, sabe? Ai fico com medo de não conseguir dá pro meu filho tudo que ele precisar. Até hoje não tá faltando nada, mas tenho medo (A6).

Preocupação porque minha mulher era nova. Então fiquei com medo de acontecer alguma coisa com ela, sei lá. Não sei direito, mas fiquei com medo. A expectativa era de meu filho nascer bem, com saúde, grande, bonito. Com saúde, né, é o que mais importa (A7).

Preocupo com tudo, né? Com saúde, com dinheiro, como que vou educar. Com tudo que pai preocupa (A4).

Tais achados corroboram com Piccinini e seus colaboradores, ${ }^{12}$ que destacam a preocupação com a saúde da companheira e do bebê, com o novo papel de educador, a situação financeira, e na espera que o filho nasça bem e que tenham um futuro pro- missor. Os pais, de um modo geral, podem apresentar muita ansiedade durante a gestação, preocupando-se com o parto, saúde do bebê e com o aumento das responsabilidades para com a família. Nesse sentido, há uma ênfase ao papel provedor do homem atrelado às preocupações identificadas. É importante destacar que o pouco conhecimento e suporte social recebido pela família, comunidade e serviços de saúde, associado à falta de maturidade nesse contexto, pode levar ao sentimento de exclusão, inutilidade, fuga de todos os aspectos da preparação para a chegada do bebê e, algumas vezes, do próprio ambiente familiar. ${ }^{12}$

A paternidade provocou mudança no que se refere às questões econômicas e de trabalho dos pais. Observou-se que a mudança no estilo de vida foi, principalmente, pela preocupação com o sustento financeiro. Dos oito entrevistados, quatro tinham empregos temporários e procuraram um serviço fixo; três deles mantiveram-se estudando; um não estudava nem trabalhava até descobrir que seria pai.

Nenhum dos dois não fazia era nada(A8).

Eu só estudava, ai agora tive que começar a trabalhar pra poder sustentar meu filho, dar a ele e a mãe tudo que precisarem, né? (A2).

As falas elucidam que a notícia de uma gravidez não planejada acarretou mudanças nos modos de viver. A mudança mais frequente é deixarem os estudos e irem à procura de um emprego, uma renda para que possam sustentar a nova família. ${ }^{13}$ A escolha entre estudar ou trabalhar é uma das situações enfrentadas por muitos adolescentes, cujo trabalho é considerado por alguns 
como meio fundamental à concretude das responsabilidades advindas da paternidade. Enquanto alguns consideram o estudo prioridade para a construção de um futuro melhor, outros simplesmente abandonam a escola e se dedicam ao trabalho. Reconhece-se, assim, a repercussão da paternidade precoce na evasão escolar, fator que pode impedir o crescimento intelectual e, portanto, a expectativa de um futuro promissor. ${ }^{14}$

Avaliação da assistência prestada pelo serviço de saúde e participação do pai no pré-natal: entre anseios e exclusão

As falas dos entrevistados são carregadas de referências a uma atenção às necessidades e aos cuidados prestados apenas à saúde da mulher. Ao adolescente pai resta um papel secundário. Isso demonstra um serviço de saúde centrado na figura da gestante, desigual no que diz respeito ao atendimento equânime do pai adolescente.

Comigo não teve nada não, mais com ela, ixi, foi bom demais. Eles até vinham aqui pegar ela, muito bom, tinha muito cuidado sabe, muito bom o trabalho deles (A5).

O atendimento foi bom. Ensinava tudo pra ela e eu só ficava olhando pra ver se eu aprendia as explicações deles, mas falava mais com ela, também ela que é a mãe, né? É por isso, mas foi tudo bom (A7).

Os serviços de saúde reproduzem um movimento sócio-histórico que supervaloriza a função biológica e social feminina de parir e cuidar e, ao homem, cabe apenas prover. Sendo assim, os serviços de saúde priorizam o ensino do cuidar à mulher e se concentram me torno do parto. ${ }^{11}$ Tal ponto de vista corrobora com outros autores, que discutem que a assistência à gravidez adolescente, em geral, é voltada ao atendimento às mulheres, pelo pré-natal convencional. ${ }^{6}$ Dessa forma, considera-se que a organização de serviços de saúde, em linhas gerais, não é estruturada de modo a inserir o pai adolescente na assistência pré-natal proposta, de maneira que esse pai permanece em segundo plano no processo de gravidez, maternidade e paternidade. ${ }^{6}$

Dos oito pais adolescentes entrevistados, cinco não acompanharam a gestante no pré-natal. As justificativas foram relacionadas à falta de incentivo e convite da companheira e do serviço de saúde.

Não participei porque não fui convidado, ora! (A8).

Porque eu acho, não sei se estou certo não, mas eu acho que é porque isso é mais para a mulher, a mãe, quem cuida mais é ela. Eu acho, e também ninguém me chamava não (A6).

Ah, acho que não é importante não, ela nem ninguém chamou, ela não importa, e eu prefiro não ir, não é importante não, o importante é dar atenção depois (A4).

Torna-se importante problematizar que as condutas e práticas dos pais entrevistados vinculam-se às expectativas dos papéis sociais relacionados ao gênero, reproduzido também pelo sistema de saúde, que, por sua vez, possuiria um papel importante na modificação de paradigmas e transformação da realidade. $\mathrm{O}$ que se percebe é que os serviços de saúde, em geral, não estão organizados de maneira a incluir o pai adolescente na assistência pré-natal, deixando-o em segundo plano. É essencial que os serviços de saúde incluam o pai adolescente na assistência, 
fazendo-o entender a importância de pensar seus anseios, trabalhar em conjunto nos modos de enfrentamento dos medos e estabelecimento de condutas positivas no processo de paternidade e mudanças de paradigmas de desigualdade de gênero na sociedade. ${ }^{15-16}$

Três pais adolescentes entrevistados acompanharam a gestante durante o pré-natal. Foram presentes nas falas sentimentos relacionados à expectativa e preocupação com a saúde e desenvolvimento do filho e da gestante. $\mathrm{O}$ apoio à companheira é apontado como elemento importante nesse processo.

Como eu falei, eu gostava de tá junto mais ela, de assumir minha filha. Tem que vê como tá a saúde deles, aprender pra ajudar ela se ela precisar né (A1).

Ué, é importante demais, tem que ser importante. A gente que é pai tem que ver os primeiro movimento, tem que dar ajuda pra companheira, tem que dá carinho pro filho que tá vindo (A5).

Em sentido contrário às imposições de papéis sociais relacionados ao gênero presentes na sociedade, observa-se nas falas citadas o envolvimento, a preocupação e expectativas em torno da paternidade. Tais iniciativas, apesar de tímidas, demonstram força em algo que contrapõe as pressões por cumprimento de papéis socialmente estabelecidos e vão em direção ao cuidado e participação ativa da paternidade.

Autores discorrem que muitos jovens estão valorizando a importância de sua participação na vinda e na vida dos seus filhos. ${ }^{4,17}$ Por sua vez, estudos demonstram que, apesar de um aparente crescimento na intenção de participação dos pais e ideologia de igualdade entre papéis a serem desempenhados entre mãe e pai, percebe-se uma distância significativa entre a fala e as condutas, com práticas bem menos equilibradas do que relatadas. ${ }^{6,9,18}$

Assim, a paternidade pode e deve ser considerada uma oportunidade para expressar sentimentos e participação ativa no cuidado dos filhos. ${ }^{17}$

\section{CONSIDERAÇõeS FINAIS}

Os achados permitiram uma reflexão e compreensão do modo como pais adolescentes vivem a experiência da paternidade. Possibilitaram, ainda, elucidar suas expectativas, medos, dificuldades encontradas na participação da gestação, mas, principalmente, demonstraram que os serviços de saúde reproduzem uma lógica social excludente e omissa em relação ao pai adolescente, determinada por questões de gênero.

Esse achado tem relevância ímpar, uma vez que as modificações nas conformações sociais, apesar de complexas e rígidas, podem ser alteradas a partir da disseminação de novos modos de pensar, fazer e cuidar. Nesse sentido, os serviços de saúde podem ser um instrumento forte para impulsionar mecanismos de mudança na rede social.

Esta pesquisa aponta para a necessidade urgente de uma nova organização dos serviços de saúde de maneira a introduzir o pai adolescente nesse contexto, para que ele possa contribuir no seu papel de cuidador, com suas subjetividades e especificidades.

Torna-se necessário que os serviços de saúde tenham uma assistência mais humanizada, equânime e transformadora com os pais adolescentes. A realização de escuta ativa e busca de compreensão dos seus anseios, medos, dúvidas; contexto familiar, social, econômico, e suas necessidades en- 
quanto adolescente e pai pode ser um passo inicial importante para o estabelecimento de um plano de intervenção e inclusão desse adolescente no processo de gestação. Outro aspecto importante é a intersetoria- lidade e transversalidade na abordagem do tema, incluindo outros equipamentos e membros da comunidade em que esses adolescentes então inseridos, para que se sintam fortalecidos por uma rede de apoio.

\section{REFERÊNCIAS}

1. Instituto Brasileiro de Geografia e estatística [serial da Internet]. Sinopse dos resultados do Censo, 2010 [citado 2016 jan. 1]. Disponível em: http://www.censo2010.ibge.gov.br/sinopse/ webservice/

2. Organização Mundial da Saúde. Young People's Health - a Challenge for Society. Report of a WHO Study Group on Young People and Health for All. Technical Report Series 731. Geneva: WHO, 1986.

3. Fundação ABRINQ. Cenário da infância e da adolescência no Brasil. Fundação ABRINQ, 2015 [citado 2016 jan. 1]. Disponível em: http://www.neca.org.br/wp-content/uploads/CenarioBrasil_LivroDeBolso_2015.pdf

4. Souza TA, Brito MEM, Frota AC, Nunes JM. Gravidez na adolescência: percepções, comportamentos e experiências de familiares. Rev Rene [periódico na Internet]; 2012 [citado 2015 nov. 27]; 13(4):794-804. Disponível em: http://www.revistarene.ufc.br/revista/index.php/revista/article/view/1074

5. Jager ME, Batista FA, Perrone CM, Santos SS, Dias ACG. O adolescente no contexto da saúde pública brasileira: reflexões sobre o Prosad. Psicol estud. 2014; 19(2):211-221.

6. Corrêa ACP, Ferriani MGC. Paternidade adolescente: um desafio a ser enfrentado pelos serviços de saúde. Cienc Cuid Saúde [periódico da Internet] 2007 [citado 2015 nov. 27]; 6(2):157163. Disponível em: http://www.periodicos.uem.br/ojs/index.php/CiencCuidSaude/article/ view/4141/2726

7. Barreto AC, Almeida IS, Ribeiro IB, Tavares KF. Paternity in the Adolescence: trends of the scientific production. Adolesc Saude. 2010; 7(2):54-59.

8. Sampaio KJAJ, Villela WV, Oliveira EM. Significados atribuídos a paternidade por adolescentes. Acta Paul Enferm. 2014; 27(1):1-5.

9. Bordignon SS, Meincke SMK, Soares MC, Schwartz E., Barlem ELD, Lunardi VL Paternidade na adolescência no contexto dos serviços de saúde, escola e comunidade. Texto contexto - enferm. 2014; 23(4):979-986.

10. Bardin L. Análise de conteúdo. Lisboa: Edições 70, 2009.

11. Alves RF, Silva RP, Ernesto MV, Lima AGB, Souza FMa. (2011). Gênero e saúde: o cuidar do homem em debate. Psicol teor prat [periódico da Internet] 2011 [citado 2016 jan. 1]; 13(3):152166. Disponível em: http://pepsic.bvsalud.org/pdf/ptp/v13n3/v13n3a12.pdf

12. Piccinini CA, Silva MR, Gonçalves TR, Lopes RS. O envolvimento paterno durante a gestação. Psicol Refl Crít [periódico da Internet] 20042011 [citado 2016 jan. 1]; 17(3):303-314. Disponível em: http://www.scielo.br/pdf/prc/v17n3/a03v17n3.pdf

13. Almeida AFF, Hardy E. Vulnerabilidade de gênero para a paternidade em homens adolescentes. Rev Saúde Pública [periódico da Internet] 2007 [citado 2016 jan. 29]; 41(4): 565-572. Disponível em: http://www.scielosp.org/scielo.php?script=sci_arttext\&pid=S0034$-89102007000400010 \& \operatorname{lng}=$ pt\&nrm $=$ iso 
14. Melo ALA, Machado MFAS, Maia ER, Sampaio KJAJ. Repercussões da paternidade na vida do adolescente. Rev Rene [periódico da Internet] 2012 [citado 2015 nov. 28]; 13(2):261-268. Disponível em: http://www.revistarene.ufc.br/revista/index.php/revista/article/view/208

15. Luz AMH, Berni NIO. Processo da paternidade na adolescência. Rev Bras Enferm [periódico da Internet] 2010 [citado 2015 dez. 1]; 63(1):43-50. Disponível em: http://www.scielo.br/scielo. php?script=sci_arttext\&pid=S0034-71672010000100008

16. Levandowski DC, Piccinini CA. Expectativas e sentimentos em relação à paternidade entre adolescentes e adultos. Psicol teor prat [periódico da Internet] 2006 [citado 2015 nov. 26]; 22(1):1728. Disponível em: http://www.scielo.br/pdf/ptp/v22n1/29840.pdf

17. Martins AC. Paternidade: repercussões e desafios para a área de saúde. Revista Pós Ciênc Soc [periódico da Internet] 2009 [citado 2015 dez. 1]; 6(11):59-73. Disponível em: http://www. ppgcsoc.ufma.br/index.php?option=com_content\&view=article\&id=307\&Itemid=114

18. Martins CA, Abreu WJCP, Figueiredo MCAB. Tornar-se pai e mãe: um papel socialmente construído. Rev Enf Ref [periódico da Internet] 2014 [citado 2015 nov. 28]; 4(2):121131. Disponível em: http://www.scielo.mec.pt/scielo.php?script=sci_arttext\&pid=S0874$-02832014000200013 \& \operatorname{lng}=$ pt. http://dx.doi.org/10.12707/RIII1394

\section{DAdos dos Autores}

\section{Gabriella Lacerda Magalhães}

Graduada em Enfermagem pelas Faculdades de Saúde e Desenvolvimento Humano Santo Agostinho de Montes Claros. Montes Claros/MG - Brasil.gabienf_lacerda@gmail.com

\section{Lívia Alencar Gomes}

Graduada em Enfermagem pelas Faculdades de Saúde e Desenvolvimento Humano Santo Agostinho de Montes Claros. Montes Claros/MG - Brasil. livialencar906@hotmail.com

\section{Rosana Franciele Botelho Ruas}

Mestre em Enfermagem pela Universidade Federal de Minas Gerais. Professora do Departamento de Enfermagem das Faculdades de Saúde e Desenvolvimento Humano Santo Agostinho de Montes Claros e do Instituto Superior de Educação Ibituruna. Montes Claros/MG - Brasil. rosanaruas@ yahoo.com.br

\section{Antônia Gonçalves De Souza}

Graduanda em Psicologia das Faculdades Integradas Pitágoras de Montes Claros. Montes Claros/ MG - Brasil. antoniagoncalves8@gmail.com

\section{Luís Paulo Souza e Souza}

Doutorando em Saúde Pública pela Faculdade de Medicina da Universidade Federal de Minas Gerais. Professor do Departamento de Medicina da Universidade Federal de São João del-Rei. São João del-Rei/SP - Brasil. luis.pauloss@hotmail.com

\section{Carla Silvana de Oliveira e Silva}

Doutora em Ciências pela Universidade Federal de São Paulo. Professora do Departamento de Enfermagem da Universidade Estadual de Montes Claros. Montes Claros/MG - Brasil. profcarlasosilva@ gmail.com 


\section{NÁdia Aléssio Velloso}

Doutora em Bioquímica Toxicológica pela Universidade Federal de Santa Maria. Professora do Instituto de Ciências da Saúde da Universidade Federal do Mato Grosso. Sinop/MT - Brasil. na.velloso@ gmail.com

Submetido em: 16-8-2016

Aceito em: 28-3-2017 